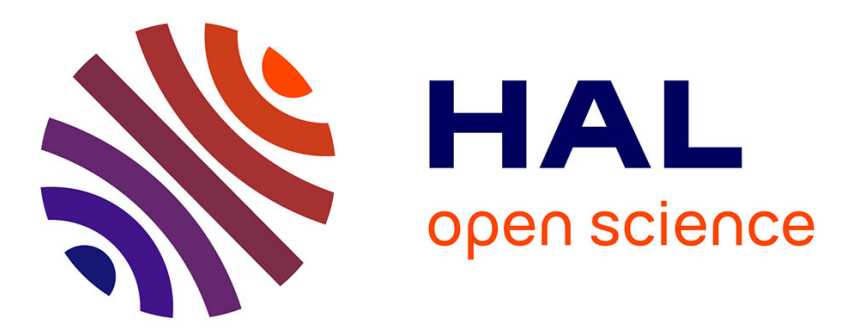

\title{
MÖSSBAUER SPECTROSCOPIC STUDIES OF IRON-SULPHUR PROTEINS WITH FOUR-IRON ACTIVE CENTRES
}

D. Dickson, C. A. Johnson, P. Middleton, J. Rush, R. Cammack, D. Hall, R. Mullinger, K. Rao

\section{To cite this version:}

D. Dickson, C. A. Johnson, P. Middleton, J. Rush, R. Cammack, et al.. MÖSSBAUER SPECTROSCOPIC STUDIES OF IRON-SULPHUR PROTEINS WITH FOUR-IRON ACTIVE CENTRES. Journal de Physique Colloques, 1976, 37 (C6), pp.C6-171-C6-175. 10.1051/jphyscol:1976636 . jpa00216746

\section{HAL Id: jpa-00216746 \\ https://hal.science/jpa-00216746}

Submitted on 1 Jan 1976

HAL is a multi-disciplinary open access archive for the deposit and dissemination of scientific research documents, whether they are published or not. The documents may come from teaching and research institutions in France or abroad, or from public or private research centers.
L'archive ouverte pluridisciplinaire HAL, est destinée au dépôt et à la diffusion de documents scientifiques de niveau recherche, publiés ou non, émanant des établissements d'enseignement et de recherche français ou étrangers, des laboratoires publics ou privés. 


\title{
MÖSSBAUER SPECTROSCOPIC STUDIES OF IRON-SULPHUR PROTEINS WITH FOUR-IRON ACTIVE CENTRES
}

\author{
D. P. E. DICKSON, C. E. JOHNSON, P. MIDDLETON and J. D. RUSH \\ Department of Physics, University of Liverpool, Liverpool, L69 3BX, UK \\ and \\ R. CAMMACK, D. O. HALL, R. N. MULLINGER and K. K. RAO \\ Department of Plant Sciences, King's College, University of London, \\ London, SE24 9JF, UK
}

\begin{abstract}
Résumé. - L'effet Mössbauer a été utilisé pour étudier la grande classe des protéines fersoufre avec centres $4 \mathrm{Fe}-4 \mathrm{~S}$. Les spectres obtenus des quatre membres de ce groupe montrent une conduite commune. Une compréhension complète théorique nécessite des lissages aux spectres obtenus d'un Hamiltonian convenable. De bons lissages sont obtenus pour les spectres des différents états redox de la ferredoxine de Bacillus stearothermophilus mesurés dans divers champs magnétiques et températures.
\end{abstract}

\begin{abstract}
A large class of iron-sulphur proteins have active centres containing four iron atoms. Mössbauer spectra obtained from four members of this group show a common pattern of behaviour. A complete theoretical understanding of these spectra requires computer fitting using a suitable Hamiltonian. Good fits have been obtained for the spectra of both redox states of Bacillus stearothermophilus ferredoxin obtained in a range of temperatures and applied magnetic fields.
\end{abstract}

1. Introduction. - The most complicated of the iron-sulphur proteins which have so far been systematically studied are those with active centres containing four iron atoms and four labile sulphur atoms. These include the high-potential iron-sulphur proteins (HiPIPs) and four-iron bacterial ferredoxins as well as the eight-iron bacterial ferredoxins which contain two centres per molecule. It is now reasonably well established that all these proteins contain very similar centres which can exist in three oxidation states : $\mathrm{C}^{+}$(formally $3 \mathrm{Fe}^{3+}$ and $1 \mathrm{Fe}^{2+}$ ) in the case of oxidized HiPIP ; $\mathrm{C}$ (formally $2 \mathrm{Fe}^{3+}+2 \mathrm{Fe}^{2+}$ ) in the case of reduced HiPIP and oxidized ferredoxin; and $\mathrm{C}^{-}$(formally $1 \mathrm{Fe}^{3+}+3 \mathrm{Fe}^{2+}$ ) in the case of reduced ferredoxin and super-reduced HiPIP.

Mössbauer studies have been carried out on the four-iron ferredoxin from Bacillus stearothermophilus [1], the HiPIP from Chromatium [2, 3, 4, 5] and the eight-iron ferredoxins from Clostridium pasteurianum $[6,7,8]$ and Chromatium $[2$, our own unpublished work].

2. Mössbauer spectra. - In the absence of magnetic effects the iron-sulphur proteins exhibit quadrupolesplit doublet spectra which can be interpreted to give information about the equivalence and valence of the iron atoms. In the proteins with four-iron centres, the situation is complex in that the spectra do not in general show either a single component or separate resolved components. The Mössbauer chemical shift is used to characterize the valence by means of a semi-empirical calibration. This leads to the formal valences quoted above. The quadrupole splitting and its temperature dependence confirms these assignments. While these formal valences cannot be regarded as trapped, there is in no case a single quadrupole doublet indicating complete delocalization of the $3 \mathrm{~d}$ electrons over all four iron atoms within the centre. Only in the spectra of reduced B. stearothermophilus ferredoxin (Fig. 1) can two doublets be completely resolved indicating that the iron atoms form two inequivalent pairs. These are interpreted as arising from two iron atoms of ferrous character and two iron atoms with valences intermediate between ferrous and ferric. At $35 \mathrm{~K}$ the more ferric component (i. e. the component with the smaller chemical shift and quadrupole splitting) has broadened into a wide band of absorption resulting from magnetic hyperfine interaction while the ferrous component remains as a doublet. This is in keeping with the assigned valences as the magnetic hyperfine interaction is less for ferrous atoms.

At low temperatures and in applied magnetic fields there is no evidence for any magnetic hyperfine interaction in the Mössbauer spectra of proteins with $\mathrm{C}$ state centres. This means that the $\mathrm{C}$ state centre has a non- 


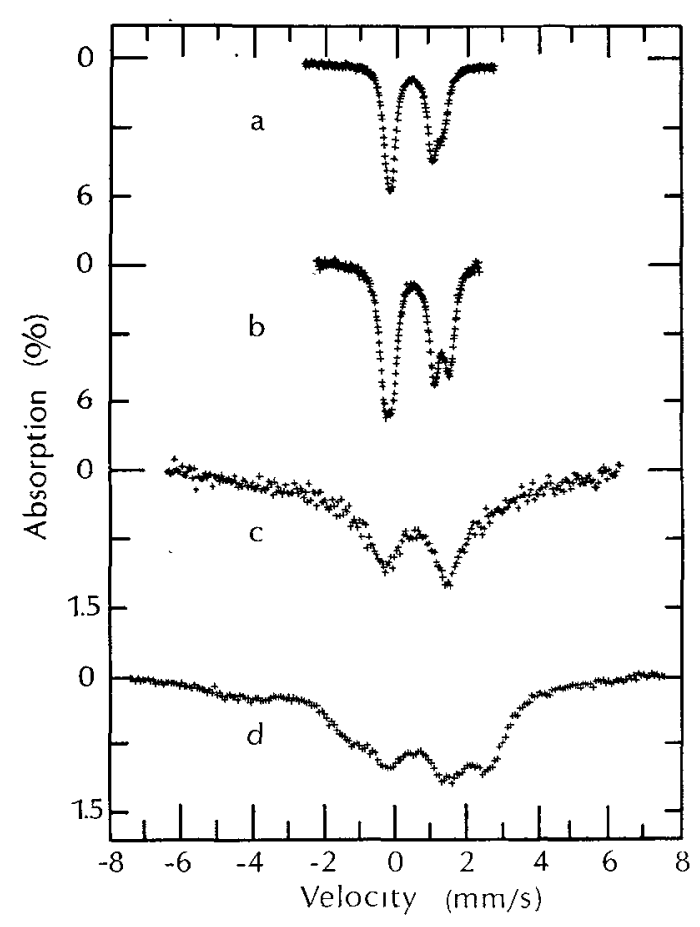

FIG. 1. - Mössbauer spectra of reduced B. stearothermophilus ferredoxin :a) at $195 \mathrm{~K} ; b$ ) at $77 \mathrm{~K} ; c$ ) at $35 \mathrm{~K}$ and $d$ ) at $4.2 \mathrm{~K}$.

magnetic ground state with total spin zero, implying antiferromagnetic coupling between the four atoms with two atoms spin-up and two atoms spin-down.

In the $\mathrm{C}^{+}$and $\mathrm{C}^{-}$state centres, with one less or one more electron, antiferromagnetic coupling gives a ground state with total spin $S=\frac{1}{2}$. Progress with computer fitting of the applied field spectra of the proteins in these magnetic states is discussed in the next section. Much information can be obtained qualitatively and in the applied field spectra of all the proteins with magnetic state centres there is direct evidence for both positive and negative hyperfine fields and hence antiferromagnetic coupling between the iron atoms $[1,4,7]$.

Magnetic hyperfine structure would be expected at low temperatures in the Mössbauer spectra of all the proteins with $\mathrm{C}^{+}$and $\mathrm{C}^{-}$state centres, even in the absence of an applied field. However, the eight-iron ferredoxins from $C$. pasteurianum and Chromatium which have two centres per molecule show broadened quadrupole-split doublets even at $1.3 \mathrm{~K}$. This anomalous behaviour has been attributed [8] to a coupling between the two centres in the molecule to give a state with total spin zero and the apparently diamagnetic Mössbauer spectra. At first sight a coupling between the two centres appears unlikely as they are approximately $1.2 \mathrm{~nm}$ apart. Although the two nearest iron atoms are appreciably closer together than this there are no direct bridging ligands between the two centres for the superexchange interaction which usually gives rise to antiferromagnetic coupling.

In order to examine this coupling theory, dimethyl sulphoxide has been applied to reduced $C$. pasteurianum ferredoxin. This unfolds the protein, thus modifying and presumably decreasing any interaction between the centres. The effect of this treatment on the Mössbauer spectrum is to change the anomalous behaviour of the native reduced eight-iron ferredoxin and to produce a broad asymmetric spectrum similar to that seen in the four-iron ferredoxin from B. stearothermophilus. This is shown in figure 2 . There is there-

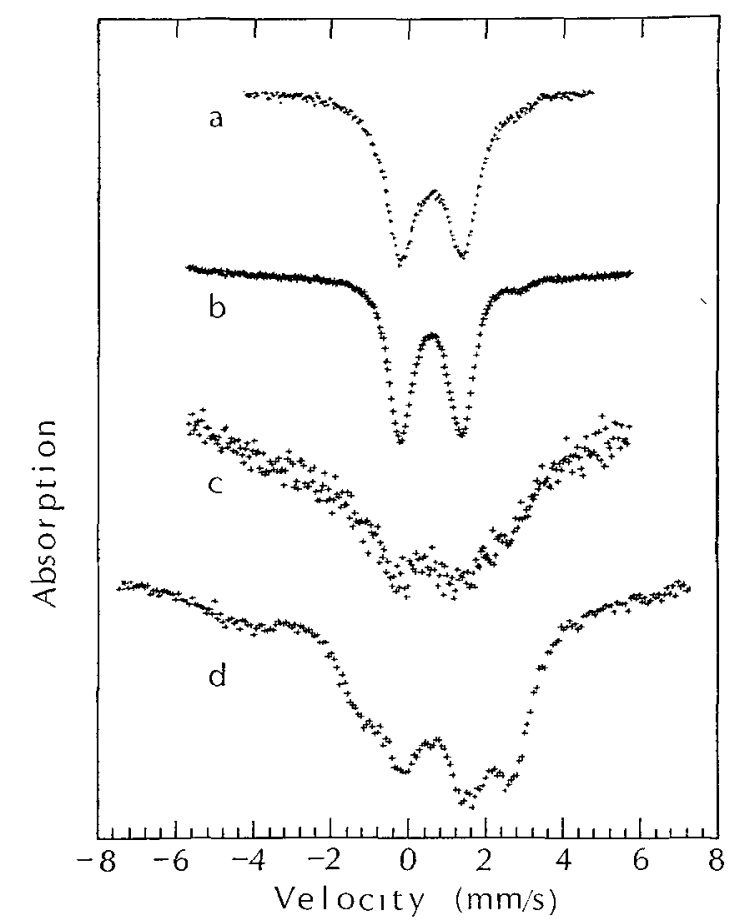

FIG. 2. - Mössbauer spectra of reduced ferredoxins at $4.2 \mathrm{~K}$ showing the effect of dimethyl sulphoxide. C. pasteurianum ferredoxin : $a$ ) native; $b$ ) in $15 \%$ dimethyl sulphoxide; c) in $80 \%$ dimethyl sulphoxide and $d$ ) native $B$. stearothermophilus ferredoxin.

fore clear evidence for an interaction between the two centres of the eight-iron ferredoxins, although the exact mechanism of this interaction is not yet understood. In high applied magnetic fields the Mössbauer spectra of Chromatium and C. pasteurianum ferredoxins are very similar to the spectra of $B$. stearothermophilus ferredoxin, suggesting that large magnetic fields break the coupling between the two centres in the eight-iron ferredoxins and give a behaviour characteristic of their four-iron centres.

3. Computer analysis. - The computer program used in this work is that of Lang and Dale [9] modified to fit spectra with up to four independent components with Hamiltonians of the form :

$$
\begin{array}{r}
\mathcal{H}=\beta \mathbf{H}_{\mathrm{app}} \cdot \mathbf{g} \cdot \mathbf{S}+\frac{Q V_{z z}}{4}\left[I_{z}^{2}-\frac{5}{4}+\frac{\eta}{3}\left(I_{x}^{2}-I_{y}^{2}\right)\right] \\
+\mathbf{I} \cdot \mathbf{A} \cdot \mathbf{S}-g_{n} \beta_{n} \mathbf{I} \cdot \mathbf{H}_{\mathrm{app}} .
\end{array}
$$

The first term is the electronic Zeeman interaction, 
the second is the nuclear quadrupole interaction, the third is the magnetic hyperfine interaction and the fourth is the direct nuclear Zeeman interaction with the applied field. The centroid of the resulting spectrum depends on an additional chemical shift term.

In all cases more than one component is required to give a good fit. Multiple component fits to spectra with overlapping components can be hazardous but if physical insight is used to limit the number of variable parameters reliable fits can be obtained. The best criteria for reliability and uniqueness of the computer fits is consistency of fitted parameters from spectra obtained over a wide range of experimental conditions.

In order to fit the spectra of the oxidized ferredoxins and reduced HiPIP in zero field only the second term of the above Hamiltonian is used : the first and fourth terms being used for applied field spectra. Figure 3

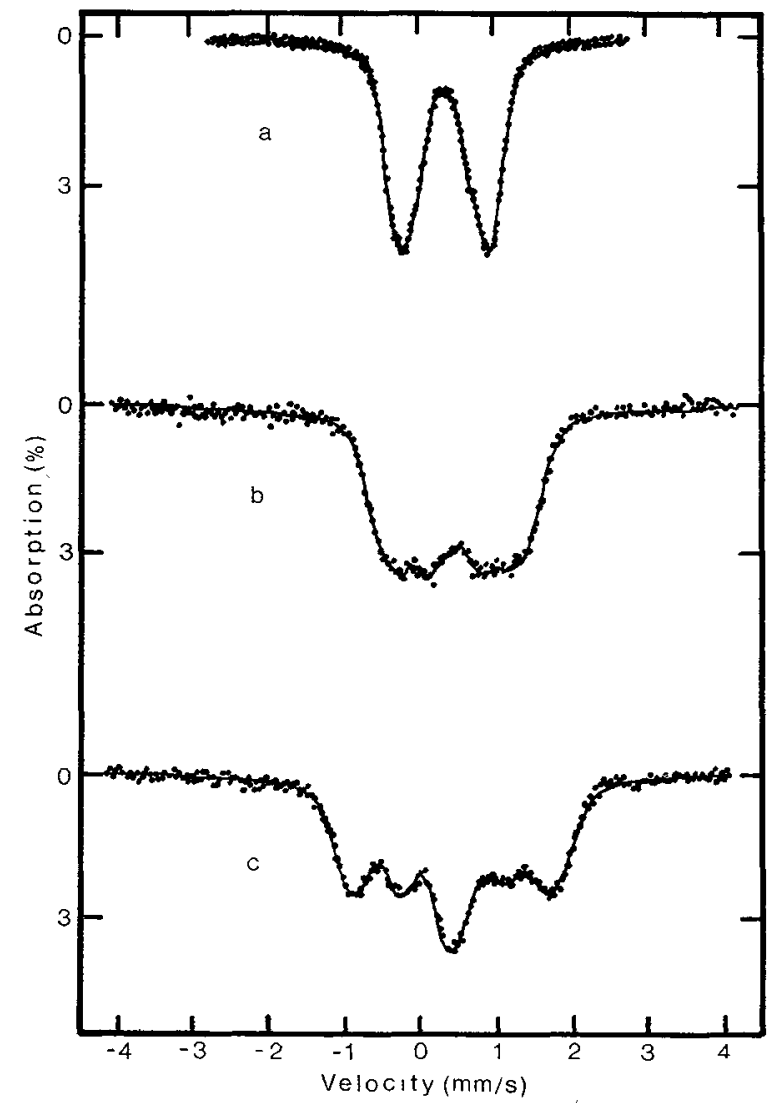

Frg. 3. - Mössbauer spectra and computer fits of oxidized B. stearothermophilus ferredoxin at $4.2 \mathrm{~K}$ in: a) zero field; b) $3.0 \mathrm{~T}$ perpendicular and $c$ ) $6.0 \mathrm{~T}$ perpendicular.

shows the spectra of oxidized B. stearothermophilus ferredoxin taken at $4.2 \mathrm{~K}$ and in applied magnetic fields, together with the least-squares computer fits. These fits use four components constrained to have the same linewidths and intensities which limits the number of variable parameters. Almost as good fits can be obtained using only two components if the linewidths and intensities are allowed to vary independently but these fits have linewidths significantly greater than the experimental value and the intensity ratios obtained do not in general relate to the number of iron atoms in the molecule if it is assumed that the recoil-free fractions are all equal. The two component fit should therefore be regarded as an approximation to a four component fit. Table 1 gives the fitted parameters for oxidized $B$. stearothermophilus ferredoxin. The good fits obtained for this protein and the others with $\mathrm{C}$ state centres confirm that $S=0$ in this state. As can be seen from table I the chemical shifts of all four iron atoms are virtually equal confirming that their valence states must be nearly the same (intermediate between ferric and ferrous). The main difference between the four iron atoms is in their quadrupole interaction which implies some inequivalence of the charge distribution at each iron site.

TABLES I AND II. - Mössbauer parameters of $B$. stearothermophilus ferredoxin. The chemical shifts relative to iron metal, $\delta$, the quadrupole splittings, $\Delta E_{\mathrm{Q}}$, and the full widths at half maximum, $\Gamma$, are quoted in $\mathrm{mm} / \mathrm{s}$. $A$-values are given in $\mathrm{mm} / \mathrm{s}$ relative to the ${ }^{57} \mathrm{Fe}$ excited state. $\eta$ is the asymmetry parameter. The numbers in brackets give the standard deviations (in units of the least significant digit) of mean parameters derived from fits to spectra obtained in a range of applied fields. See text for further details.

TABLE I

Oxidized Ferredoxin

\begin{tabular}{ccllll} 
& & \multicolumn{1}{c}{1} & \multicolumn{1}{c}{2} & \multicolumn{1}{c}{3} & \multicolumn{1}{c}{4} \\
$195 \mathrm{~K}$ & $\delta$ & 0.37 & 0.37 & 0.37 & 0.37 \\
& $\Delta E_{\mathrm{Q}}$ & 1.08 & 0.83 & 0.70 & 0.55 \\
& $\Gamma$ & 0.29 & 0.29 & 0.29 & 0.29 \\
$77 \mathrm{~K}$ & $\delta$ & 0.43 & 0.43 & 0.43 & 0.42 \\
& $\Delta E_{\mathrm{Q}}$ & 1.36 & 1.07 & 0.86 & 0.57 \\
& $\Gamma$ & 0.27 & 0.27 & 0.27 & 0.27 \\
$4.2 \mathrm{~K}$ & $\delta$ & $0.42(1)$ & $0.43(2)$ & $0.42(2)$ & $0.42(2)$ \\
& $\Delta E_{\mathrm{Q}}$ & $1.50(6)$ & $1.20(3)$ & $1.10(9)$ & $0.66(1)$ \\
& $\Gamma$ & $0.27(1)$ & $0.27(1)$ & $0.27(1)$ & $0.27(1)$ \\
& $\eta$ & $0.7(1)$ & $0.7(1)$ & $0.9(1)$ & $0.9(1)$
\end{tabular}

TABLE II

Reduced Ferredoxin

\begin{tabular}{ccl} 
& \multicolumn{1}{c}{1} & \multicolumn{1}{c}{2} \\
$\delta$ & 0.53 & 0.44 \\
$\Delta E_{\mathrm{Q}}$ & 1.54 & 1.13 \\
$\Gamma$ & 0.35 & 0.28 \\
$\delta$ & 0.59 & 0.49 \\
$\Delta E_{\mathrm{Q}}$ & 1.84 & 1.20 \\
$\Gamma$ & 0.36 & 0.36 \\
$\delta$ & $0.58(2)$ & $0.50(2)$ \\
$\Delta E_{\mathrm{Q}}$ & $1.89(6)$ & $1.32(6)$ \\
$\eta$ & $0.32(4)$ & $0.78(9)$ \\
$A_{x}$ & $-1.30(3)$ & $1.56(7)$ \\
$A_{y}$ & $-0.66(8)$ & $1.60(4)$ \\
$A_{z}$ & $-0.42(4)$ & $1.37(7)$
\end{tabular}


Fitting the applied field spectra of the proteins in the magnetic state presents more difficulty. All four terms of the above Hamiltonian are used, the $g$-factors are assumed to be isotropic and set equal to 2 and the $A$-tensor and the electric field gradient tensor are assumed to have the same principal axis system. The first term of the Hamiltonian is assumed large compared with the other three so that the electron spin is decoupled from the nuclear spin. This corresponds to applied fields greater than about $0.002 \mathrm{~T}$. In the calculation, the electron Zeeman problem is solved first, then $S$ is replaced by its quantum mechanical expectation value and the nuclear problem is solved in the effective field approximation. The relaxation is assumed to be slow. By passing over a large number of field directions appropriately distributed over an octant of a sphere the total array of absorption energies and intensities is accumulated for the present case of a polycrystalline absorber.

All of the proteins with magnetic state centres show evidence that the iron atoms are not all equivalent and so a one component fit would be inadequate. The spectra in applied magnetic fields exhibit both positive and negative hyperfine fields and hence there must be iron atoms with different sets of $A$-values, and in addition, the quadrupole-split doublet spectra obtained at higher temperatures all show some broadening and asymmetry indicating inequivalence between the iron atoms. The spectra of reduced $B$. stearothermophilus ferredoxin presents the best evidence in that at $77 \mathrm{~K}$ there are two resolved quadrupole-split doublets of equal intensity (Fig. 1b). This resolution into doublets is unique amongst the proteins so far investigated and provides a good basis for fitting the applied field spectra with two components. While this leads to linewidths slightly greater than the experimental values it would be unreasonable to use as many as four components with such a complex fitting procedure.

The spectra of reduced $B$. stearothermophilus ferredoxin taken in both perpendicular and parallel applied fields between $\mathrm{O} .1 \mathrm{~T}$ and $6 \mathrm{~T}$ have been fitted using two components of equal linewidth and intensity but allowing the other parameters to vary independently. The fits give values of chi-squared close to one per degree of freedom and the parameters obtained are found to be closely similar for the spectra obtained over the whole range of applied fields. This consistency of the fitted parameters is good evidence for the reliability of the fitting procedure. A selection of these spectra and fits are shown in figure 4, and the fitted parameters are given in table II. The values of the chemical shift and quadrupole splitting obtained from the applied field fits are consistent with those from the higher temperature spectra. They indicate that component 1 corresponds to two high-spin ferrous atoms while component 2 arises from two iron atoms with a more ferric character (essentially $\mathrm{Fe}^{2 \frac{1}{2}+}$ ). These assignments are confirmed by the highly anisotropic

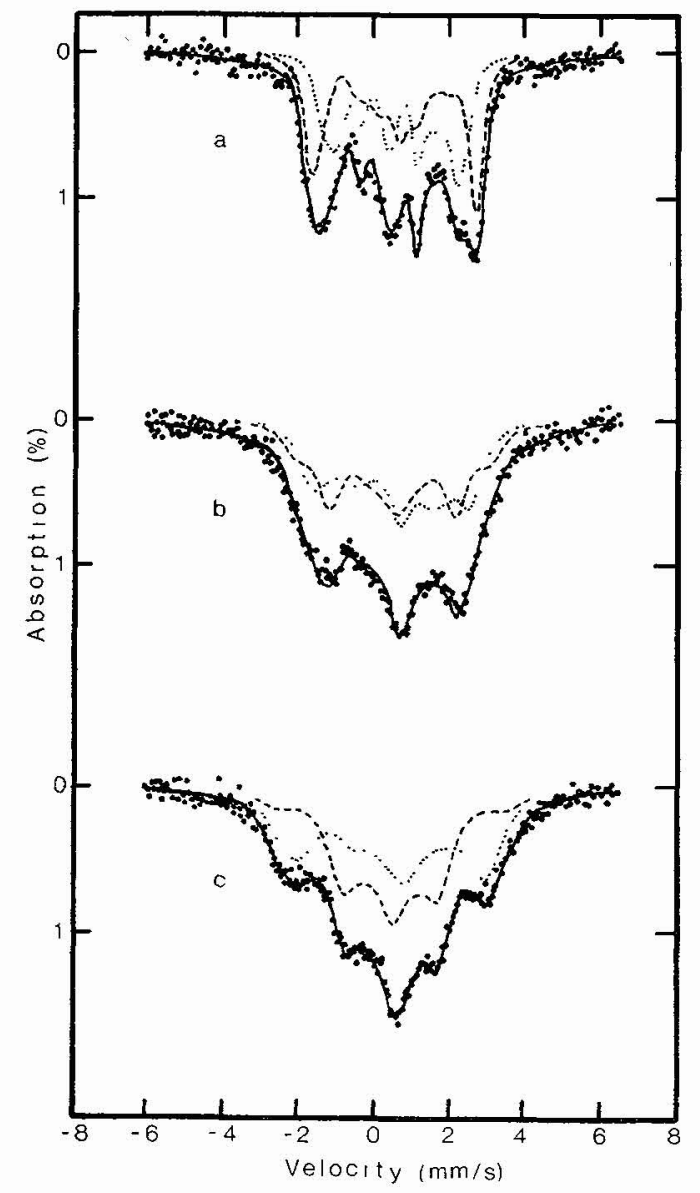

FIG. 4. - Mössbauer spectra and computer fits of reduced B. stearothermophilus ferredoxin at $4.2 \mathrm{~K}$ in parallel applied magnetic fields of : a) $0.1 \mathrm{~T}$; b) $3.0 \mathrm{~T}$ and $c$ ) $6.0 \mathrm{~T}$. Components 1 and 2 are given by the dotted and dashed lines.

$A$-values of component 1 . The negative $A$-values of the ferrous component correspond to a positive hyperfine field and a magnetic moment directed antiparallel to the applied field.

There is a possibility of another set of fits with the opposite sign of the quadrupole splitting and different $A$-values for the ferrous component but these fits give larger values of chi-squared and much greater variation in the value of the fitted parameters between fits of spectra taken in different fields. Fitting of spectra taken in applied magnetic fields at higher temperatures when the relaxation is fast could completely resolve this ambiguity.

4. Discussion. - The spectra of reduced C. pasteurianum ferredoxin in applied magnetic fields at $4.2 \mathrm{~K}$ have been previously fitted [10] on the assumption that in this protein all eight iron atoms are equivalent. The fits used a single component Hamiltonian with two parameters corresponding to the parallel and perpendicular components of the effective hyperfine field. By using a large linewidth reasonable fits were obtained to spectra taken in lower fields but the simulations of 
higher field spectra were appreciably different from those obtained experimentally.

The present two component fits to the spectra of reduced $B$. stearothermophilus ferredoxin appear to give a more consistent picture. While the uniqueness of any computer fit may be called into question the $77 \mathrm{~K}$ spectrum of this protein leaves little doubt that two components are required.

The high applied field spectra of the reduced eightiron ferredoxins are very similar to those of the reduced four-iron ferredoxins and this suggests that these spectra could be fitted in a similar way. This should lead to a better understanding of the degree of inequivalence of the iron atoms in the eight-iron ferredoxins. Work is also in progress in interpreting the parameters given in table II to give a more complete picture of the iron orbitals within the active centre.

The computer analysis described in the previous section confirms the model for the four-iron centre of this group of proteins proposed previously by Dickson et al. [11] as a result of a more qualitative interpretation of the spectra of $C$. pasteurianum ferredoxin and Chromatium HiPIP. In the $\mathrm{C}$ state the centre contains two spin-up iron atoms and two spin-down iron atoms. There is fast hopping or delocalization of the sixth $3 \mathrm{~d}$ electrons between each pair of iron atoms and all iron atoms have an effective valence $\mathrm{Fe}^{2} \frac{1}{2}+$. On reduction of the ferredoxin the centre gains one $3 \mathrm{~d}$ electron which goes to the pair of spin-down iron atoms which become $\mathrm{Fe}^{2+}$ leaving the spin-up pair $\mathrm{Fe}^{2 \frac{1}{2}+}$.

\section{References}

[1] Mullinger, R. N., CAmmack, R., RaO, K. K., Hall, D. O., Dickson, D. P. E., Johnson, C. E., Rush, J. D. and Simopoulos, A., Biochem. J. 151 (1975) 75.

[2] Moss, T. H., Bearden, A. J., Bartsch, R. G., Cusanovich, M. A. and SAN Pietro, A., Biochemistry 7 (1968) 1591.

[3] Evans, M. C. W., Hall, D. O. and Johnson, C.E., Biochem. J. 119 (1970) 289.

[4] Dickson, D. P. E., Johnson, C. E., Cammack, R., Evans, M. C. W., Hall, D. O. and RaO, K. K., Biochem. J. 139. (1974) 105.

[5] Dickson, D. P. E. and Cammack, R., Biochem. J. 143 (1974) 763.
[6] Blomstrom, D. C., Knight, E., Jr., Phillips, W. D. and Weiner, J. R., Proc. Nat. Acad. Sci. US 51 (1964) 1085.

[7] Thompson, C. L., Johnson, C. E., Dickson, D. P. E., Cammack, R., Hall, D. O., Weser, U. and Rao, K. K., Biochem. J. 139 (1974) 97.

[8] Gersonde, K., Schlaak, H. E., Breitenbach, M., Parak, F., Excher, H., Zgorzalla, W., Kalvius, M. G. and MAYer, A., Eur. J. Biochem. 43 (1974) 307.

[9] LANG, G. and DaLE, B. W., Nucl. Instr. Meth. 116(1974) 567.

[10] Eichir, H., Parak, F., Bogner, L. and Gersonde, K., Z. Naturforsch. 29c (1974) 683.

[11] Dickson, D. P. E., Johnson, C. E., Thompson, C. L. Cammack, R., Evans, M. C. W., Hall, D. O., Rao, K. K. and Weser, U., $J$ Physique Colloq. 35 (1974) C 6-343. 